\title{
Growth and nutrient efficiency of Betula alnoides clones in response to phosphorus supply
}

\author{
L. Chen, H.Y. Jia, J. Zeng, B. Dell
}

Chen L., Jia H.Y., Zeng J., Dell B., 2016. Growth and nutrient efficiency of Betula alnoides clones in response to phosphorus supply. Ann. For. Res. 59(2): 199-207.

Abstract. As phosphorus deficiency limits the productivity of many plantation forests in Asia, there is considerable interest in developing phosphorus-efficient clones for the region through targeted breeding programs. Therefore, we determined growth, nutrient concentrations and nutrient absorption and utility efficiencies of four Betula alnoides clones (C5, C6, 1-202 and BY1) in response to six phosphorus levels of $0,17,52,70,140$ and $209 \mathrm{mg} \mathrm{P}^{\mathrm{P}}$ plant $^{-1}$ coded as P1 to P6, respectively. Maximum growth occurred in the P4, P5 and P6 plants since they had the largest height, biomass, leaf area and branch number. Phosphorus application increased the phosphorus concentrations of all clones. Nutrient loading was achieved with the P6 treatment because growth and biomass were not significantly higher, but root, stem and leaf phosphorus concentrations were approximately twice those of P4 plants. Clone BY1 had the highest phosphorus-efficiency, and is recommended for field application due to its maximum root collar diameter, biomass, root/shoot ratio, leaf area, nutrient absorption and utility efficiency among the four clones. The findings will help to improve the nutrient efficiency of this species in plantation forestry in Asia.

Keywords growth, nutrient concentrations, nutrient absorption and utility efficiencies, phosphorus.

Authors. Lin Chen, Hong Yan Jia (jiahy-ectf@hotmail.com) - The Experimental Center of Tropical Forestry, CAF, Pingxiang 532600, Guangxi, China; Jie Zeng (zengdasan@hotmail.com) - Research Institute of Tropical Forestry, CAF, Guangzhou 510520, Guangdong, China; Bernard Dell - Division of Research \& Development, Murdoch University, Western Australia 6150, Australia.

Manuscript received March 19, 2016; revised October 20, 2016; accepted October 27, 2016; online first October 31, 2016.

\section{Introduction}

Phosphorus is a major element constraining the growth of fast-growing species, particular- ly in phosphorus-poor soils (Elser et al. 2007, Vitousek et al. 2010). Applying phosphorus fertilizer is a common practice to overcome the phosphorus limitation and to promote the 
successful establishment and productivity of tree species (Bown \& Van den Driessche 2005, DesRochers et al. 2006, Singh \& Singh 2011). However, only $10-25 \%$ of inorganic phosphorus applied in fertilizer is taken up by plants, which can lead to serious soil and water pollution (Syers et al. 2008) if the bulk of the phosphorus is not strongly adsorbed by soil surfaces. Thus, efforts to develop high nutrient-efficient plants through breeding programs have been undertaken exploring inter- and intra- specific variations for plant growth, physiology and nutrient efficiency (Lamhamedi et al. 2000, Mari et al. 2003, Pang et al. 2010, Urich et al. 2003).

Phosphorus efficiency has been shown to be closely linked to the ability to absorb phosphorus from the soil and the efficiency of allocation of phosphorus within the plant (Hidaka \& Kitayama 2011, van de Wiel et al. 2016). For example, superior clones of white spruce ( $P i$ cea glauca) had faster height growth, longer needles, different tannin structure and distribution, greater N, P and K use efficiencies, higher root growth potential and net photosynthesis compared to the parent family (Lamhamedi et al. 2000). The nutrient-efficient hybrid aspen clone (Populus tremula $\times$ P. tremuloides) with high growth saved around $5 \%$ of nutrients in the short term, but different nutrient storage strategies between clones may be regarded as a possible way to save nutrients in the long run (Rytter \& Stener 2003). For two Chinese fir clones (Cunninghamia lanceolata) with high phosphorus efficiency, the adaption of these clones to low phosphorus condition was attributed to increased phosphorus acquisition and utilization efficiencies (Wu et al. 2011).

Betula alnoides Buch.-Ham. ex D. Don is a broad-leaved and fast-growing species in southern China which is favored for reforestation in recent years because of its wood quality and ecological functions (Zeng et al. 2006). The nitrogen loading requirement of $B$. alnoides has been studied (Chen et al. 2010), however the phosphorus requirement of this species being considered for further reforestation is unknown. Generally, the soils of southern China limit the growth of plantation tree species (Xu et al. 2002). Therefore, we investigated the growth and nutrition responses of four $B$. alnoides clones to phosphorus. The objectives of this study are to: (1) determine the optimal phosphorus requirement for maximum growth and nutrient uptake of B. alnoides; and (2) identify any superior clones with high phosphorus efficiency and favorable biomass production in order to improve the establishment success of $B$. alnoides in the field.

\section{Materials and methods}

Four clones of Betula alnoides ex D. Don, coded as C5, C6, 1-202 and BY1, were selected with good performance in the nursery and recent employment in reforestation. Clones C5, C6 and BY1 were from Longzhou County and clone 1-202 was from Baise City, in Guangxi, China. Clonal plants were initially grown in a mixture of $60 \%$ composted bark, 30\% composted sawdust and 10\% charred bark (bark charcoal) in the nursery of the Experimental Center of Tropical Forestry, CAF at Pingxiang City, Guangxi, China. After two months, healthy plants with equal height of about 4 cm were selected on April 25, 2011, the roots rinsed clean by tap water followed by deionized water, then transplanted into plastic pots $(17.5 \times 11 \times 12 \mathrm{~cm}$, height, upper and bottom diameters) filled with a high-pressure steam pasteurized mixture of peat, vermiculite, perlite (v:v:v, 3:2:2). The pots were lined with two plastic bags to prevent water and nutrient leaching. During the experimental period, the average daily light intensity, temperature and relative humidity of the greenhouse ranged from 72 to $376 \mu \mathrm{mol}$ photon $\mathrm{m}^{-2} \mathrm{~s}^{-1}, 26$ to $34^{\circ} \mathrm{C}$ and 55 to $80 \%$, respectively. To avoid pests and disease, the media surface was sprayed weekly with $2 \%$ carbendazim or chlorpyrifos solution from 2 weeks after transplanting. 
A split-plot experiment design was conducted with four replications, the main plot consisted of six phosphorus levels: $0,17,52,70$, 140 and 209 mg P plant $^{-1}$, coded as P1, P2, P3, P4, P5 and P6, respectively, and the subplot included four B. alnoides clones: C5, C6, 1-202 and BY1. Each subplot had 12 plants, thus a total of 288 plants $(12$ plants $\times 6 \mathrm{P}$ treatments $\times$ 4 replications) for each clone. The plants were watered with equal amounts of deionized water by the method of Chen et al. (2012). Fertilization started at eighteen days after transplanting. Plants were supplied with $50 \mathrm{ml}$ of nutrient solutions once a week for 12 weeks. The basal nutrient solution contained $6 \mathrm{mM}$ $\mathrm{KNO}_{3}, 4 \mathrm{mM} \mathrm{Ca}\left(\mathrm{NO}_{3}\right)_{2} \cdot 4 \mathrm{H}_{2} \mathrm{O}, 2 \mathrm{mM} \mathrm{MgSO}$, $0.1 \mathrm{mM}$ Fe-EDTA, $0.05 \mathrm{mM} \mathrm{H}_{3} \mathrm{BO}_{3}, 0.01 \mathrm{mM}$ $\mathrm{MnCl}_{2} .4 \mathrm{H}_{2} \mathrm{O}, 0.0008 \mathrm{mM} \mathrm{ZnCl}, 0.0003 \mathrm{mM}$ $\mathrm{CuCl}_{2} .2 \mathrm{H}_{2} \mathrm{O}, 0.0001$ and $\mathrm{mM} \mathrm{MoO}_{3}$. Phosphorus was supplied as $\mathrm{NaH}_{2} \mathrm{PO}_{4} \cdot 2 \mathrm{H}_{2} \mathrm{O}$ as a series of concentrations which doubled every three weeks from initial $0,0.25,0.75,1,2$ and $3 \mathrm{mM}$ to final $0,2,6,8,12$ and $24 \mathrm{mM}$ for the six treatments, respectively. The nutrient solutions were poured onto the surface of the potting mix carefully avoiding any contact with the shoot.

Just prior to fertilization, 10 representative plants were chosen from each clone and combined to determine the initial dry weight $(0.07 \mathrm{~g}$ plant $^{-1}$ on average), and then for analyzing the initial plant concentrations of total nitrogen (12.83 $\mathrm{g} \mathrm{kg}^{-1}$ ), phosphorus (7.83 $\mathrm{g} \mathrm{kg}^{-1}$ ) and potassium $\left(15.79 \mathrm{~g} \mathrm{~kg}^{-1}\right)$. One week after the last fertilization, the height, root collar diameter and number of branches were measured. Furthermore, five plants were randomly selected from each subplot and then divided into roots, stems and leaves separately. The whole plants were emerged in tap water and washed carefully by hand to remove the fine roots from the peat mixture. Leaf area was measured for each plant according to Chen et al. (2012). After that, these components were separately composited for each subplot, and dried at $80^{\circ} \mathrm{C}$ for $48 \mathrm{~h}$ to determine root, stem and leaf dry weight, and ground by a portable crusher for subsequent chemical analysis. Plant material was wet-digested in a block digester using $\mathrm{H}_{2} \mathrm{SO}_{4}-\mathrm{HClO}_{4}$ mixture solutions. The digests were analyzed for total $\mathrm{N}$ by the titration method, total $\mathrm{P}$ by the molybdenum blue method and total $\mathrm{K}$ by atomic absorption spectroscopy (Chen et al. 2012).

Normality of data was checked with one-sample K-S test, and homogeneity of variance test was done. These tests confirmed that the data were of normal distribution and equal variance. Two-way ANOVAs were then conducted with general linear model to examine the main and interaction effects of phosphorus and clone at aspects of growth, nutrient concentrations, nutrient absorption efficiencies (NAE, PAE and KAE) and nutrient utility efficiencies (NUE, PUE and KUE) by SPSS 16.5 (SPSS Institute Inc. 2003). Significant treatment means were further compared by Duncan's multiple range tests at the 5\% level. The NAE, PAE and KAE were defined as nitrogen, phosphorus and potassium contents in every plant, and NUE, PUE and KUE as dry weight divided by nitrogen, phosphorus and potassium contents of each plant, respectively.

\section{Results}

\section{Growth performance}

Plant height, root collar diameter, biomass, leaf area and number of branches differed significantly with phosphorus supply and clone $(P<0.01$, Table 1). Additionally, there was an interaction between phosphorus supply and clone for height and branch number $(P<0.05$, Table 1) but not for the other growth parameters $(P>0.05$, Table 1$)$.

With increase in phosphorus supply, the root to shoot ratio decreased significantly from 0.35 in P1 to 0.22 in P2 but was not affected at higher phosphorus supply (Table 1). However, other growth parameters increased gradually 
Table 1 Effects of phosphorus supply and clone on growth of Betula alnoides

\begin{tabular}{|c|c|c|c|c|c|c|}
\hline & \multicolumn{6}{|c|}{ Growth indices } \\
\hline & $\begin{array}{l}\text { Height } \\
(\mathrm{cm})\end{array}$ & $\begin{array}{c}\text { Root collar } \\
\text { diameter }(\mathrm{mm})\end{array}$ & $\begin{array}{l}\text { Biomass } \\
\left(\text { g plant }^{-1}\right)\end{array}$ & $\begin{array}{l}\text { Root/shoot } \\
\text { ratio }\end{array}$ & $\begin{array}{l}\text { Leaf area } \\
\left(\mathrm{cm}^{2} \text { plant }{ }^{-1}\right)\end{array}$ & Branch number \\
\hline \multicolumn{7}{|c|}{ Phosphorus supply } \\
\hline $\mathrm{P} 1$ & $18.2(0.4)^{\mathrm{d}}$ & $2.31(0.04)^{\mathrm{e}}$ & $0.87(0.23)^{\mathrm{d}}$ & $0.35(0.01)^{\mathrm{a}}$ & $19.2(3.9)^{\mathrm{d}}$ & $6.5(0.2)^{\mathrm{d}}$ \\
\hline $\mathrm{P} 2$ & $34.8(0.4)^{\mathrm{c}}$ & $3.40(0.04)^{\mathrm{d}}$ & $3.66(0.23)^{\mathrm{c}}$ & $0.22(0.01)^{b}$ & $139.3(4.0)^{\mathrm{c}}$ & $16.1(0.2)^{\mathrm{c}}$ \\
\hline $\mathrm{P} 3$ & $37.5(0.4)^{\mathrm{b}}$ & $3.73(0.04)^{\mathrm{c}}$ & $4.34(0.23)^{b}$ & $0.21(0.01)^{b}$ & $170.7(4.0)^{\mathrm{b}}$ & $17.0(0.2)^{\mathrm{b}}$ \\
\hline P4 & $38.5(0.4)^{\mathrm{ab}}$ & $3.84(0.04)^{\mathrm{c}}$ & $4.59(0.23)^{\mathrm{ab}}$ & $0.19(0.01)^{\mathrm{b}}$ & $184.9(3.4)^{\mathrm{a}}$ & $18.0(0.2)^{\mathrm{a}}$ \\
\hline P5 & $39.1(0.4)^{\mathrm{a}}$ & $3.98(0.04)^{b}$ & $4.89(0.23)^{\mathrm{ab}}$ & $0.20(0.01)^{\mathrm{b}}$ & $192.4(4.0)^{\mathrm{a}}$ & $18.1(0.2)^{\mathrm{a}}$ \\
\hline P6 & $39.3(0.4)^{\mathrm{a}}$ & $4.18(0.04)^{\mathrm{a}}$ & $5.07(0.23)^{\mathrm{a}}$ & $0.20(0.01)^{\mathrm{b}}$ & $190.1(4.0)^{\mathrm{a}}$ & $18.2(0.2)^{\mathrm{a}}$ \\
\hline \multicolumn{7}{|c|}{ Clone } \\
\hline $\mathrm{C} 5$ & $32.1(0.3)^{\mathrm{d}}$ & $3.35(0.04)^{\mathrm{c}}$ & $3.08(0.34)^{\mathrm{c}}$ & $0.21(0.01)^{\mathrm{b}}$ & $128.6(3.5)^{\mathrm{c}}$ & $14.9(0.1)^{\mathrm{c}}$ \\
\hline C6 & $36.5(0.3)^{\mathrm{a}}$ & $3.70(0.04)^{b}$ & $3.95(0.34)^{b}$ & $0.23(0.01)^{\mathrm{b}}$ & $159.0(3.1)^{\mathrm{a}}$ & $16.4(0.1)^{\mathrm{a}}$ \\
\hline $1-202$ & $34.2(0.3)^{\mathrm{c}}$ & $3.43(0.04)^{\mathrm{c}}$ & $3.57(0.34)^{\mathrm{bc}}$ & $0.21(0.01)^{b}$ & $149.0(3.2)^{\mathrm{b}}$ & $15.6(0.1)^{\mathrm{b}}$ \\
\hline BY1 & $35.4(0.3)^{\mathrm{b}}$ & $3.82(0.04)^{\mathrm{a}}$ & $5.01(0.34)^{\mathrm{a}}$ & $0.28(0.01)^{\mathrm{a}}$ & $161.2(3.1)^{\mathrm{a}}$ & $15.5(0.1)^{\mathrm{b}}$ \\
\hline \multicolumn{7}{|c|}{ ANOVA } \\
\hline Ph. s. & $0.000 * *$ & $0.000 * *$ & $0.000 * *$ & $0.000 * *$ & $0.000 * *$ & $0.000 * *$ \\
\hline $\mathrm{Cl}$. & $0.000 * *$ & $0.000 * *$ & $0.000 * *$ & $0.000 * *$ & $0.000 * *$ & $0.000 * *$ \\
\hline $\begin{array}{l}\text { Ph. s. } \\
\times \mathrm{Cl} \text {. }\end{array}$ & $0.002 * *$ & 0.153 & 0.922 & 0.077 & 0.259 & $0.025^{*}$ \\
\hline
\end{tabular}

Notes. P1, P2, P3, P4, P5 and P6 treatments represent supply of 0, 17, 52, 70, 140 and $209 \mathrm{mg} \mathrm{P} \mathrm{plant}^{-1}$, respectively. Figures in parentheses are standard errors. Values followed by the same letters in a column are not significantly different among treatments at 0.05 level according to Duncan's multiple range tests. "**” and “**” represent signi- ficant difference among treatments at 0.05 and 0.01 levels, respectively. Abbreviations: $\mathrm{Ph}$. s. - phosphorus supply, Cl. - clone.

and then remained stable, with plateau values reached in P4 for height, biomass, leaf area and number of branches. The P6 plants had the highest root collar diameter (Table 1).

Compared with the control (P1), phosphorus additions increased the height, root collar diameter, biomass, leaf area and number of branches by $91-116 \%, 47-81 \%, 321-483 \%$, $626-902 \%$ and $148-180 \%$, respectively (Table 1). Of the four clones, clone $\mathrm{C} 5$ had the poorest growth performance. Clone BY1 had superior root collar diameter, biomass, root to shoot ratio, and leaf area, being approximately $14 \%, 63 \%, 33 \%$ and $25 \%$ higher than those of clone $\mathrm{C} 5$, respectively. However, clone $\mathrm{C} 6$ had maximal height and number of branches, about $14 \%$ and $10 \%$ higher, respectively, than those of clone C5 (Table 1).

\section{Nutrient concentrations}

There were significant effects of phosphorus supply on root, stem and leaf nutrient concentrations $(P<0.05$, Table 2$)$. However, the clones did not differ with respect to phosphorus concentrations $(P>0.05$, Table 2$)$ but differed strongly for nitrogen concentrations in root and leaf as well as potassium concentrations in leaf and stem $(P<0.01$, Table 2$)$. Overall, there were significant interactions between phosphorus supply and clone for root, stem and leaf phosphorus concentrations as well as for stem nitrogen concentration $(P<0.05$, Table 2$)$.

The root, stem and leaf nutrient concentra- 
Table 2 Effects of phosphorus supply and clone on nutrient concentrations of Betula alnoides

\begin{tabular}{|c|c|c|c|c|c|c|c|c|c|}
\hline & \multicolumn{9}{|c|}{ Nutrient concentration $\left(\mathrm{g} \mathrm{kg}^{-1}\right)$} \\
\hline & \multicolumn{3}{|c|}{ Root } & \multicolumn{3}{|c|}{ Stem } & \multicolumn{3}{|c|}{ Leaf } \\
\hline & $\mathrm{N}$ & $\mathrm{P}$ & K & $\mathrm{N}$ & $\mathrm{P}$ & K & $\mathrm{N}$ & $\mathrm{P}$ & K \\
\hline \multicolumn{10}{|c|}{ Phosphorus } \\
\hline $\mathrm{P} 1$ & $14.0(0.3)^{\mathrm{a}}$ & $1.2(0.1)^{\mathrm{e}}$ & $13.7(0.4)^{\mathrm{c}}$ & $12.8(0.3)^{\mathrm{a}}$ & $0.8(0.1)^{\mathrm{f}}$ & $13.8(0.3)^{\mathrm{c}}$ & $19.2(0.3)^{\mathrm{a}}$ & $1.1(0.1)^{\mathrm{e}}$ & $16.2(0.2)^{\mathrm{c}}$ \\
\hline $\mathrm{P} 2$ & $12.6(0.3)^{\mathrm{b}}$ & $1.5(0.1)^{\mathrm{e}}$ & $15.0(0.4)^{\mathrm{b}}$ & $8.1(0.3)^{b}$ & $1.2(0.1)^{\mathrm{e}}$ & $15.3(0.3)^{\mathrm{b}}$ & $17.6(0.3)^{b}$ & $1.6(0.1)^{\mathrm{d}}$ & $17.5(0.2)^{b}$ \\
\hline P3 & $12.4(0.3)^{\mathrm{b}}$ & $2.5(0.1)^{\mathrm{d}}$ & $16.2(0.4)^{\mathrm{a}}$ & $7.8(0.3)^{\mathrm{b}}$ & $2.5(0.1)^{\mathrm{d}}$ & $16.5(0.3)^{\mathrm{a}}$ & $18.2(0.3)^{\mathrm{b}}$ & $2.2(0.1)^{\mathrm{c}}$ & $17.6(0.2)^{\mathrm{b}}$ \\
\hline $\mathrm{P} 4$ & $11.7(0.3)^{\mathrm{bc}}$ & $3.5(0.1)^{\mathrm{c}}$ & $15.7(0.4)^{\mathrm{ab}}$ & $7.9(0.32)^{\mathrm{b}}$ & $3.3(0.1)^{\mathrm{c}}$ & $16.7(0.3)^{\mathrm{a}}$ & $17.9(0.3)^{\mathrm{b}}$ & $2.4(0.1)^{\mathrm{c}}$ & $17.7(0.2)^{\mathrm{b}}$ \\
\hline P5 & $11.4(0.3)^{\mathrm{c}}$ & $5.7(0.1)^{\mathrm{b}}$ & $14.6(0.4)^{\mathrm{bc}}$ & $7.6(0.3)^{b}$ & $5.2(0.1)^{\mathrm{b}}$ & $16.9(0.3)^{\mathrm{a}}$ & $17.6(0.3)^{\mathrm{b}}$ & $3.6(0.1)^{\mathrm{b}}$ & $18.1(0.2)^{\mathrm{b}}$ \\
\hline P6 & $11.0(0.3)^{\mathrm{c}}$ & $7.1(0.1)^{\mathrm{a}}$ & $13.7(0.4)^{\mathrm{c}}$ & $7.3(0.3)^{\mathrm{b}}$ & $6.4(0.1)^{\mathrm{a}}$ & $16.9(0.3)^{\mathrm{a}}$ & $17.3(0.3)^{\mathrm{b}}$ & $4.9(0.1)^{\mathrm{a}}$ & $18.7(0.2)^{\mathrm{a}}$ \\
\hline \multicolumn{10}{|c|}{ Clone } \\
\hline $\mathrm{C} 5$ & $12.8(0.3)^{\mathrm{a}}$ & $3.7(0.1)$ & $14.7(0.3)$ & $8.7(0.3)$ & $3.3(0.1)$ & $16.7(0.2)^{\mathrm{a}}$ & $18.5(0.2)^{\mathrm{a}}$ & $2.7(0.1)$ & $17.2(0.2)^{b}$ \\
\hline C6 & $11.2(0.3)^{\mathrm{b}}$ & $3.4(0.1)$ & $14.4(0.3)$ & $8.3(0.3)$ & $3.2(0.1)$ & $16.2(0.2)^{\mathrm{ab}}$ & $18.6(0.2)^{\mathrm{a}}$ & $2.7(0.1)$ & $17.4(0.2)^{\mathrm{b}}$ \\
\hline $1-202$ & $12.3(0.3)^{\mathrm{a}}$ & $3.6(0.1)$ & $14.9(0.3)$ & $9.1(0.3)$ & $3.1(0.1)$ & $15.9(0.2)^{\mathrm{bc}}$ & $18.4(0.2)^{\mathrm{a}}$ & $2.6(0.1)$ & $17.3(0.2)^{b}$ \\
\hline BY1 & $12.3(0.3)^{\mathrm{a}}$ & $3.6(0.1)$ & $15.2(0.3)$ & $8.3(0.3)$ & $3.3(0.1)$ & $15.3(0.2)^{\mathrm{c}}$ & $16.5(0.2)^{\mathrm{b}}$ & $2.6(0.1)$ & $18.6(0.2)^{\mathrm{a}}$ \\
\hline \multicolumn{10}{|c|}{ ANOVA } \\
\hline Ph. s. & $0.000^{* *}$ & $0.000 * *$ & $0.000 * *$ & $0.000^{* *}$ & $0.000 * *$ & $0.000^{* *}$ & $0.000 * *$ & $0.000^{* *}$ & $0.000 * *$ \\
\hline $\mathrm{Cl}$. & $0.001 * *$ & 0.277 & 0.262 & 0.122 & 0.256 & $0.000^{* *}$ & $0.000^{* *}$ & 0.900 & $0.000^{* *}$ \\
\hline $\begin{array}{l}\mathrm{Ph} . \mathrm{s} . \\
\times \mathrm{Cl}\end{array}$ & 0.656 & $0.002 * *$ & 0.670 & $0.005^{* *}$ & $0.020^{*}$ & 0.092 & 0.998 & $0.002 * *$ & 0.191 \\
\hline
\end{tabular}

Notes. P1, P2, P3, P4, P5 and P6 treatments represent supply of 0, 17, 52, 70, 140 and $209 \mathrm{mg} \mathrm{P}$ plant $^{-1}$, respectively. Figures in parentheses are standard errors. Values followed by the same small letters in a column are not significantly different among treatments at $P<0.05$ according to Duncan's multiple range tests. “*” and "***" represent significant difference among treatments at 0.05 and 0.01 levels, respectively. Abbreviations: Ph. s. - phosphorus supply, $\mathrm{Cl}$. - clone.

tions showed a similar trend among clones as the amount of phosphorus addition increased. For example, phosphorus concentrations increased gradually with the increase in phosphorus supply, reaching the maximum at P6 (Table 2). In contrast, stem and leaf nitrogen concentrations decreased rapidly and then tended to be stable above P2. The potassium concentrations gradually increased from P1 to $\mathrm{P} 3$, and then declined in the roots or remained stable in the stem and leaf potassium. Of four clones, clone BY1 had the lowest leaf nitrogen and stem potassium concentrations but highest leaf potassium concentration (Table 2).

\section{Nutrient absorption and utility efficien- cies}

Nitrogen, phosphorus and potassium absorp- tion efficiencies (NAE, PAE and KAE) and utility efficiencies (NUE, PUE and KUE) were all significantly influenced by phosphorus supply $(P<0.01$, Table 3$)$. Moreover, there were marked differences in the NAE, PAE, KAE and NUE $(P<0.01$, Table 3$)$, unlike for PUE and KUE, among clones $(P>0.05$, Table $3)$. However, the only significant interaction between phosphorus supply and clone was in KUE $(P<0.05$, Table 3$)$.

With the increase in phosphorus supply, NAE, PAE and KAE of the four clones increased first, and then NAE and KAE tended to be constant after P3 or P4, while the PAE increased continuously (Table 3). As for nutrient utility efficiencies, PUE and KUE decreased gradually as phosphorus addition increased, and then maintained stable after P5 and P2, respectively. However, NUE increased with 
Table 3 Effects of phosphorus supply and clone on nutrient absorption efficiency (nitrogen, NAE; phosphorus, PAE; potassium, KAE) and nutrient utility efficiency (nitrogen, NUE; phosphorus, PUE; potassium, KUE) of Betula alnoides

\begin{tabular}{|c|c|c|c|c|c|c|}
\hline & $\begin{array}{c}\text { NAE } \\
\left(\text { mg plant }^{-1}\right)\end{array}$ & $\begin{array}{c}\text { PAE } \\
\left(\text { mg plant }^{-1}\right)\end{array}$ & $\begin{array}{c}\text { KAE } \\
\left(\text { mg plant }^{-1}\right)\end{array}$ & $\begin{array}{c}\text { NUE } \\
\left(\mathrm{g} \mathrm{mg}^{-1}\right)\end{array}$ & $\begin{array}{c}\text { PUE } \\
\left(\mathrm{g} \mathrm{mg}^{-1}\right)\end{array}$ & $\begin{array}{c}\mathrm{KUE} \\
\left(\mathrm{g} \mathrm{mg}^{-1}\right)\end{array}$ \\
\hline \multicolumn{7}{|c|}{ Phosphorus supply } \\
\hline $\mathrm{P} 1$ & $13.68(2.64)^{\mathrm{c}}$ & $0.97(1.47)^{\mathrm{e}}$ & $12.83(3.64)^{\mathrm{d}}$ & $0.06(0.00)^{\mathrm{c}}$ & $1.08(0.03)^{\mathrm{a}}$ & $0.07(0.00)^{\mathrm{a}}$ \\
\hline $\mathrm{P} 2$ & $49.34(2.53)^{\mathrm{b}}$ & $5.14(1.25)^{\mathrm{d}}$ & $59.67(3.64)^{\mathrm{c}}$ & $0.07(0.00)^{\mathrm{ab}}$ & $0.70(0.03)^{\mathrm{b}}$ & $0.06(0.00)^{\mathrm{b}}$ \\
\hline P3 & $59.15(2.53)^{\mathrm{a}}$ & $9.96(1.25)^{\mathrm{c}}$ & $73.53(3.64)^{b}$ & $0.07(0.00)^{\mathrm{ab}}$ & $0.43(0.03)^{\mathrm{c}}$ & $0.06(0.00)^{b}$ \\
\hline P4 & $62.04(2.53)^{\mathrm{a}}$ & $12.91(1.20)^{\mathrm{c}}$ & $77.99(3.64)^{\mathrm{ab}}$ & $0.07(0.00)^{\mathrm{b}}$ & $0.35(0.03)^{\mathrm{d}}$ & $0.06(0.00)^{\mathrm{b}}$ \\
\hline P5 & $64.74(2.53)^{\mathrm{a}}$ & $22.13(1.20)^{\mathrm{b}}$ & $83.89(3.64)^{\mathrm{ab}}$ & $0.07(0.00)^{\mathrm{ab}}$ & $0.22(0.03)^{\mathrm{e}}$ & $0.06(0.00)^{\mathrm{b}}$ \\
\hline P6 & $64.65(2.53)^{\mathrm{a}}$ & $30.15(1.25)^{\mathrm{a}}$ & $87.22(3.64)^{\mathrm{a}}$ & $0.08(0.00)^{\mathrm{a}}$ & $0.18(0.03)^{\mathrm{e}}$ & $0.06(0.00)^{\mathrm{b}}$ \\
\hline \multicolumn{7}{|c|}{ Clone } \\
\hline $\mathrm{C} 5$ & $43.47(2.07)^{\mathrm{c}}$ & $11.13(1.13)^{\mathrm{b}}$ & $51.59(2.97)^{\mathrm{c}}$ & $0.07(0.00)^{\mathrm{c}}$ & $0.48(0.03)$ & $0.06(0.00)$ \\
\hline C6 & $53.61(2.07)^{\mathrm{b}}$ & $13.55(0.98)^{\mathrm{b}}$ & $66.50(2.97)^{\mathrm{b}}$ & $0.07(0.00)^{\mathrm{b}}$ & $0.48(0.02)$ & $0.06(0.00)$ \\
\hline $1-202$ & $49.37(2.13)^{b}$ & $12.36(0.98)^{\mathrm{b}}$ & $59.25(2.97)^{\mathrm{bc}}$ & $0.07(0.00)^{\mathrm{bc}}$ & $0.48(0.02)$ & $0.06(0.00)$ \\
\hline BY1 & $62.61(2.07)^{\mathrm{a}}$ & $17.13(1.06)^{\mathrm{a}}$ & $86.07(2.97)^{\mathrm{a}}$ & $0.08(0.00)^{\mathrm{a}}$ & $0.54(0.03)$ & $0.06(0.00)$ \\
\hline \multicolumn{7}{|c|}{ ANOVA } \\
\hline Ph.s. & $0.000 * *$ & $0.000 * *$ & $0.000 * *$ & $0.000 * *$ & $0.000 * *$ & $0.000 * *$ \\
\hline $\mathrm{Cl}$. & $0.000 * *$ & $0.001 * *$ & $0.000 * *$ & $0.000 * *$ & 0.203 & 0.587 \\
\hline $\begin{array}{l}\text { Ph.s. } \\
\times \mathrm{Cl}\end{array}$ & 0.950 & 0.555 & 0.825 & 0.636 & 0.526 & $0.014 *$ \\
\hline
\end{tabular}

Notes. P1, P2, P3, P4, P5 and P6 treatments represent supply of 0, 17, 52, 70, 140 and $209 \mathrm{mg} \mathrm{P} \mathrm{plant}^{-1}$, respectively. Figures in parentheses are standard errors. Values followed by the same small letters in a column are not significantly different among treatments at $P<0.05$ according to Duncan's multiple range tests. "*” and "**” represent significant difference among treatments at 0.05 and 0.01 levels, respectively. Abbreviations: Ph. s. - phosphorus supply, $\mathrm{Cl}$. - clone.

the increase in phosphorus supply up to P2 and then was unchanged. Notably, clone BY1 showed the highest NAE, NUE, PAE and KAE among the four clones (Table 3), which was in agreement with its superior growth performance (Table 1).

\section{Discussion}

Phosphorus addition strongly promoted growth of the four $B$. alnoides clones, indicating that phosphorus deficiency was a major limiting factor for plant development in the nursery environment (Warren \& Adams 2002) similar to studies on aspen and its hybrids (Liang \& Chang 2004), and three Leucadendron culti- vars (Silber et al. 2000). However, the root to shoot ratio of $B$. alnoides plants showed little response to phosphorus addition in the present study. This might be attributed to an insensitive response of root to shoot ratio to variable amounts of phosphorus where the nitrogen supply remains constant (Garrish et al. 2010).

The survival and early performance of outplanted nursery stock at the establishment stage are likely to be more influenced by internal nutrient retranslocation than by the current nutrient supply, hence the benefit of nutrient loading in nursery production (Bown et al. 2012, Folk \& Grossnickle 2000, Salifu \& Timmer 2003). The P4, P5 and P6 treatments all resulted in maximum growth measured as height, biomass, leaf area and number of 
branches. This implies that the $\mathrm{P} 4$ treatment (70 mg P plant ${ }^{-1}$ ) was sufficient for the growth of $B$. alnoides clones. Furthermore, as the P6 treatment (209 mg P plant ${ }^{-1}$ ) did not cause phosphorus toxicity symptoms even though phosphorus concentrations were twice those in P4 plants, this suggests that $B$. alnoides clones had high phosphorus uptake ability, and nutrient loading can be achieved at the highest phosphorus treatment (Salifu et al. 2009, Timmer et al 1997). One probable mechanism to prevent the accumulation of inorganic phosphorus (Pi) reaching toxic concentrations in $B$. alnoides was the conversion of $\mathrm{Pi}$ into organic storage compounds, e.g. phytic acid (Schachtman et al. 1998). As the phosphorus supply in soils in south China is commonly limiting for tree growth (Tan et al. 2015, Xu et al. 2002), it is recommended that luxury phosphorus additions be applied to nursery stock prior to outplanting in nutrient-poor or weed-prone sites. Apart from the amount of fertilizer, the nutrient addition ratio and rate should also be considered to improve nutrient efficiency in the future (Isaac et al. 2011, Kelly \& Ericsson 2003).

Variations often occur in growth and nutrient use efficiency among clones, which provides a potential advantage for developing nutrient-efficient plants through breeding programs (Baligar et al. 2001). For example, some clones of poplar (Populus deltoides $\times P$. cathayana and $P$. deltoides $\times P$. simonii) were selected for reforestation under low phosphorus stress because they absorbed more phosphorus and thus grew better than other clones through increasing rhizosphere acidification and affinity of roots to capture phosphate (Zhang et al. 2003a, 2003b). Natural hybrid clones (e.g. Eucalyptus PF1) were progressively replaced by artificial hybrid clones $(E$. urophylla $\times E$. grandis) around Pointe-Noire in Congo since they had lower biomass and nutrient use efficiencies but greater nutrient contents loss when harvesting compared to artificial hybrid clones (Safou-Matondo et al.
2005). In Betula, clone BY1 had the largest root collar diameter, dry weight, leaf area, root and shoot ratio among the four clones tested. The allocation of more resources to the root, so as to absorb more water and nutrients to support plant growth, helps to explain the greater productivity in this clone (Zhang et al. 2013). This can also be confirmed from its higher nutrient absorption efficiencies and NUE (Bown et al. 2012; Folk \& Grossnickle 2000). Clone BY1 had lower leaf nitrogen concentration but higher leaf potassium concentration compared with other clones, suggesting that nitrogen dilution and synergism between phosphorus and potassium ions were occurred in the fast-growing clones of $B$. alnoides.

\section{Conclusions}

The growth, nutrient concentrations and nutrient efficiencies were more influenced by phosphorus supply than clones or the interaction effect. Although phosphorus supply with 70 mg P plant ${ }^{-1}$ (P4) was sufficient for B. alnoides plants, supply with $209 \mathrm{mg} \mathrm{P}^{\mathrm{P}}$ plant $^{-1}$ (P6) is recommended for higher quality clones of this species, so they have greater fitness to endure phosphorus-deficient soils commonly distributed in south China after out-planting. Clone BY1 performed the best with the maximum biomass, root to shoot ratio and internal nutrient supply. Further research on physiological plasticity, such as leaf traits, organic acid and mycorrhizal responses of $B$. alnoides clones to phosphorus supply should be undertaken to better understand the adaptive mechanisms of plants to low phosphorus contents of growing media or soils (Plassard \& Dell 2010, Niu et al. 2013, Richardson et al. 2011, Xie et al. 2014, Zhao et al. 2013).

\section{Acknowledgments}

This study was supported by The Minis- 
try of Science and Technology of China (2012BAD01B0504 and 2012BAD21B0102). We thank Cai-Lan Meng at the Experimental Center of Tropical Forestry, CAF, for her assistance in the nursery. We are also grateful to Le-Su Yang and Bin Yu at the Research Institute of Tropical Forestry, CAF, for nutrient determinations.

\section{References}

Baligar V. C., Fageria N. K., He Z. L., 2001. Nutrient use efficiency in plants. Communications in Soil Science and Plant Analysis 32(7-8): 921-950. DOI: 10.1081/ CSS-100104098

Bown H. E., Watt M. S., Clinton P. W., Mason E. G., 2012. The influence of $\mathrm{N}$ and $\mathrm{P}$ supply and genotype on $\mathrm{N}$ remobilization in containerized Pinus radiata plants. Cienciae Investigación Agraria 39(3): 505-520. DOI: 10.4067/S0718-16202012000300010

Brown K. R., Van den Driessche R., 2005. Effects of nitrogen and phosphorus fertilization on the growth and nutrition of hybrid poplars on Vancouver Island. New Forests 29(1): 89-104. DOI: 10.1007/s11056-0045418-4

Chen L. Zeng J., Xu D. P., Zhao Z. G., Guo J. J., Lin K. Q., Sha E., 2010. Effect of exponential nitrogen loading on the growth and foliar nutrient status of Betula alnoides seedlings. Silvae Sinicae 46(5): 35-40. (in Chinese)

Chen L., Zeng J., Jia H. Y., Zeng J., Guo W. F., Cai D. X., 2012. Growth and nutrient uptake dynamics of Mytilaria laosensis seedlings under exponential and conventional fertilizations. Soil Science and Plant Nutrition 58(5): 618-626. DOI: 10.1080/00380768.2012.708879

DesRochers A., Van den Driessche R., Thomas B. R., 2006. NPK fertilization at planting of three hybrid poplar clones in the boreal region of Alberta. Forest Ecology and Management 232(1): 216-225. DOI: $10.1016 /$ j. foreco.2006.06.004

Elser J. J., Bracken M. E., Cleland E. E., Gruner D. S., Harpole W. S., Hillebrand H., Ngai J. T., Seabloom E. W., Shurin J. B., Smith J. E., 2007. Global analysis of nitrogen and phosphorus limitation of primary producers in freshwater, marine and terrestrial ecosystems. Ecology Letters 10(12): 1135-1142. DOI: $10.1111 / \mathrm{j} .1461-$ 0248.2007.01113.x

Folk R. S., Grossnickle S. C., 2000. Stock-type patterns of phosphorus uptake, retranslocation, net photosynthesis and morphological development in interior spruce seedlings. New Forests 19(1): 27-49. DOI: 10.1023/A:1006618312161

Garrish V., Cernusak L. A., Winter K., Turner B. L., 2010. Nitrogen to phosphorus ratio of plant biomass versus soil solution in a tropical pioneer tree, Ficus insipida.
Journal of Experimental Botany 61(13): 3735-3748. DOI: $10.1093 /$ jxb/erq183

Hidaka A., Kitayama K., 2011. Allocation of foliar phosphorus fractions and leaf traits of tropical tree species in response to decreased soil phosphorus availability on Mount Kinabalu, Borneo. Journal of Ecology 99(3): 849-857. DOI: 10.1111/j.1365-2745.2011.01805.x

Isaac M. E., Harmand J. M., Drevon J. J., 2011. Growth and nitrogen acquisition strategies of Acacia senegal seedlings under exponential phosphorus additions. Journal of Plant Physiology 168(8): 776-781. DOI: 10.1016/j.jplph.2010.10.011

Kelly J. M., Ericsson T., 2003. Assessing the nutrition of juvenile hybrid poplar using a steady state technique and a mechanistic model. Forest Ecology and Management 180(1): 249-260. DOI: 10.1016/S03781127(02)00564-9

Lamhamedi M. S., Chamberland H., Bernier P. Y., Tremblay F. M., 2000. Clonal variation in morphology, growth, physiology, anatomy and ultrastructure of container-grown white spruce somatic plants. Tree Physio- logy 20(13): 869-880. DOI: 10.1093/treephys/20.13.869

Liang H., Chang S. X., 2004. Response of trembling and hybrid aspens to phosphorus and sulfur fertilization in a Gray Luvisol: growth and nutrient uptake. Canadian Journal of Forest Research 34(7): 1391-1399. DOI: 10.1139/x04-022

Mari S., Jansson G., Jonsson A., 2003. Genetic variation in nutrient utilization and growth traits in Picea abies seedlings. Scandinavian Journal of Forest Research 18(1): 19-28. DOI: 10.1080/02827581.2003.10383134

Niu Y. F., Chai R. S., Jin G. L., Wang H., Tang C. X., Zhang Y. S., 2013. Responses of root architecture development to low phosphorus availability: a review. Annals of Botany 112: 391-408. DOI: 10.1093/aob/mcs285

Pang J., Tibbett M., Denton M. D., Lambers H., Siddique K. H. M., Bolland M. D. A., Revell C. K., Ryan M. H., 2010. Variation in seedling growth of 11 perennial legumes in response to phosphorus supply. Plant and Soil 328(1-2): 133-143. DOI: 10.1007/s11104-0090088-9

Plassard C., Dell B., 2010. Phosphorus nutrition of mycorrhizal trees. Tree Physiology 30(9): 1129-1139. DOI: 10.1093/treephys/tpq063

Richardson A. E., Lynch J. P., Ryan P. R., Delhaize E., Smith F. A., Smith S. E., Harvey P. R., Ryan M. H., Veneklaas E. J., Lambers H., Oberson A., Culvenor R. A., Simpson R. J., 2011. Plant and microbial strategies to improve the phosphorus efficiency of agriculture. Plant and Soil 349(1-2): 121-156. DOI: 10.1007/ s11104-011-0950-4

Rytter L., Stener L. G., 2003. Clonal variation in nutrient content in woody biomass of hybrid aspen. Silva Fennica 37(3): 313-324. DOI: $10.14214 /$ sf.491

Safou-Matondo R., Deleporte P., Laclau J. P., Bouillet J. P., 2005. Hybrid and clonal variability of nutrient content and nutrient use efficiency in Eucalyptus stands in 
Congo. Forest Ecology and Management 210(1): 193204. DOI: $10.1016 /$ j.foreco.2005.02.049

Salifu K. F., Jacobs D. F., Birge Z. K., 2009. Nursery nitrogen loading improves field performance of bareroot oak seedlings planted on abandoned mine lands. Restoration Ecology 17(3): 339-349. DOI: 10.1111/j.1526100X.2008.00373.x

Salifu K. F., Timmer V. R., 2003. Optimizing nitrogen loading of Picea mariana seedlings during nursery culture. Canadian Journal of Forest Research 33(7): 12871294. DOI: 10.1139/x03-057

Schachtman D. P., Reid R. J., Ayling S. M., 1998. Phosphorus uptake by plants: from soil to cell. Plant Physiology 116(2): 447-453. DOI: 10.1104/pp.116.2.447

Silber A., Ganmore-Neumann R., Ben-Jaacov J., 2000. The response of three Leucadendron cultivars (Proteaceae) to phosphorus levels. Scientia Horticulturae 84(1): 141149. DOI: $10.1016 / \mathrm{S} 0304-4238(99) 00116-8$

Singh B., Singh G., 2011. Phosphorus enhanced establishment, growth, nutrient uptake, and productivity of Dalbergia sissoo seedlings maintained at varying soil water stress levels in an indian arid zone. Journal of Sustainable Forestry 30(6): 480-495. DOI: 10.1080/10549811.2010.550256

Syers J. K., Johnston A. E., Curtin D., 2008. Efficiency of soil and fertilizer phosphorus use: Reconciling changing concepts of soil phosphorus behaviour with agronomic information. FAO Fertilizer and Plant Nutrition Bulletin 18.

Tan L., He Y. J., Qin L., Chen S. Z., 2015. Characteristics of nutrient contents and storages in Castanopsis hystrix and Betula alnoides. Guihaia 35(1): 69-74. (in Chinese)

Timmer V. R., 1997. Exponential nutrient loading: a new fertilization technique to improve seedling performance on competitive sites. New Forests 13(1-3): 279-299. DOI: 10.1023/A:1006502830067

Urich R., Coronel I., Silva D., Cuberos M., Wulff R. D., 2003. Intraspecific variability in Commelina erecta: response to phosphorus addition. Canadian Journal of Botany 81(9): 945-955. DOI: 10.1139/b03-089

van de Wiel C. C., van der Linden C. G., Scholten O. E., 2016. Improving phosphorus use efficiency in agriculture: opportunities for breeding. Euphytica 207(1): 1-22. DOI: 10.1007/s10681-015-1572-3

Vitousek P. M., Porder S., Houlton B. Z., Chadwick O. A., 2010. Terrestrial phosphorus limitation: mechanisms, implications, and nitrogen-phosphorus interactions. Ecological Applications 20(1): 5-15. DOI: 10.1890/080127.1

Warren C. R., Adams, M. A., 2002. Phosphorus affects growth and partitioning of nitrogen to Rubisco in Pinus pinaster. Tree Physiology 22(1): 11-19. DOI: 10.1093/ treephys/22.1.11

Wu P., Ma X., Tigabu M., Wang C., Liu A., Oden P. C., 2011. Root morphological plasticity and biomass production of two Chinese fir clones with high phosphorus efficiency under low phosphorus stress. Canadian Journal of Forest Research 41(2): 228-234. DOI: 10.1139/ X10-198

Xie X., Weng B., Cai B., Dong Y., Yan C., 2014. Effects of arbuscular mycorrhizal inoculation and phosphorus supply on the growth and nutrient uptake of Kandelia obovata (Sheue, Liu \& Yong) seedlings in autoclaved soil. Applied Soil Ecology 75: 162-171. DOI: 10.1016/j. apsoil.2013.11.009

Xu D., Dell B., Malajczuk N., Gong M., 2002. Effects of $\mathrm{P}$ fertilisation on productivity and nutrient accumulation in a Eucalyptus grandis $\times$ E. urophylla plantation in southern China. Forest Ecology and Management 161(1): 89-100. DOI: 10.1016/S03781127(01)00485-6

Zeng J., Guo W. F., Zhao Z. G., Weng Q. J., Yin G. T., Zheng H. S., 2006. Domestication of Betula alnoides in China: current status and perspectives. Forestry Research 19(3): 379-384. (in Chinese)

Zhang H. C., Wang G. P., Xu T. Z., Xu C. K., Hu Z. Y., 2003a. Effects of rhizosphere acidification on phosphorus efficiency in clones of poplar. Chinese Journal of Applied Ecology 14(10): 1607-1611. (in Chinese)

Zhang H. C., Wang G. P., Xu T. Z., Xu C. K., Hu Z. Y., 2003b. Phosphate uptake characteristics of kinetics and phosphorus efficiency in clones of poplar. Scientia Silvae Sinicae 39(6): 40-46. (in Chinese)

Zhang Y., Zhou Z., Yang Q., 2013. Genetic variations in root morphology and phosphorus efficiency of Pinus massoniana under heterogeneous and homogeneous low phosphorus conditions. Plant and Soil 364(1-2): 93-104. DOI: 10.1007/s11104-012-1352-y

Zhao T. T., Zhao N. X., Gao Y. B., 2013. Ecophysiological response in leaves of Caragana microphylla to different soil phosphorus levels. Photosynthetica 51(2): 245-251. DOI: $10.1007 / \mathrm{s} 11099-013-0016-3$ 